\title{
Vale de Lágrimas: mulheres recolhidas no sertão de Minas Gerais na segunda metade do século XVIII
}

\section{Valley of Tears: women in prayer institutions in Minas Gerais during the second half of the $18^{\text {th }}$ Century}

Ana Cristina Pereira Lage*

\begin{abstract}
Resumo
Pretende-se discutir os indícios de letramento religioso na Casa de Oração do Vale de Lágrimas (c.1750 - c.1816), próxima à Vila de Minas Novas, na região norte da capitania de Minas Gerais. A instituição recebeu diversas mulheres: solteiras, casadas ou viúvas para que se dedicassem à Oração e à instrução necessária para uma determinada formação religiosa. A documentação consultada demonstra a instrução e a capacidade de letramento que era exigido das recolhidas. Os indícios de letramento, tanto para a celebração do Ofício Divino, quanto para a formação nas Artes Liberais, estabelecem os princípios de letramento religioso na instituição. Pretende-se ainda analisar a transferência das recolhidas para o Arraial de Santa Cruz da Chapada em 1780 .
\end{abstract}

Palavras-chaves: Recolhimento. Educação. Gênero.

\begin{abstract}
This article intends to discuss the evidence of religious literacy in the House of Prayer of Valley of Tears (c.1750 - c.1816), near the Village of Minas Novas, in the northern region of the captaincy of Minas Gerais. The institution received several women: single, married or widowed women to give their lives to prayer and instruction required for a particular religious background. The documentation consulted demonstrates the ability of literacy instruction and what was required of collected. The evidence of literacy for both the celebration of the Divine Office, and for training in the liberal arts, establish the principles of religious literacy in the institution. We also intend to examine the transfer of collected for the Village of Santa Cruz da Chapada in 1780.
\end{abstract}

Keywords: Gathering. Education. Gender.

\footnotetext{
* Doutorado em Educação pela Universidade Federal de Minas Gerais. Professora dos cursos de Bacharelado em Humanidades e Licenciatura em História e do Mestrado Profissional Interdisciplinar de Ciências Humanas da Universidade Federal dos Vales do Jequitinhonha e Mucuri - Campus Mucuri. E-mail: anaplage@uol.com.br
} 


\section{Introdução}

Conhecida inicialmente como Casa de Oração do Vale de Lágrimas, a instituição aqui analisada surgiu por volta de 1750, próxima à Vila de Minas Novas, na região norte de Minas Gerais. Posteriormente, em 1780, quando a instituição foi transferida para o Arraial de Santa Cruz da Chapada, foi denominada como Recolhimento de São João da Chapada e ainda é possível encontrar documentação que refere-se à mesma instituição como Recolhimento de Sant'Anna da Chapada.

A Vila de Minas Novas, fundada em 1730 como Arraial de Nossa Senhora de Bom Sucesso do Fanado, foi desanexada politicamente da Capitania da Bahia em 1757, quando passou para a subscrição da Comarca do Serro Frio na Capitania de Minas Gerais. Eclesiasticamente continuou vinculada ao Arcebispado da Bahia até 1853. Esta particularidade da região acarreta a busca de documentos em arquivos diversos, tanto mineiros, quanto baianos.

Segundo José Joaquim da Rocha, em 1788 a Vila de Minas Novas vivia da exploração de ouro e de diamantes. Nos anos de pouca chuva, a população sofria pela falta de alimentos e do baixo abastecimento da região. O clima era quente e seco e toda a água provinha do Rio Araçuaí. A margem deste rio foi escolhida para a instalação do Recolhimento do Vale de Lágrimas por volta de $1750 .{ }^{1}$

A instituição foi fundada pelo padre Manoel dos Santos que, após ser atingido por um raio e sobrevivido, prometeu angariar esmolas e estabelecer um recolhimento feminino no sertão da capitania mineira. Sua fundação esteve ligada a uma visão sobrenatural de um eclesiástico, muito comum nos relatos de fundação de outras instituições do mesmo tipo. Após a sua salvação, o padre então "[...] applicou os seus bens todos á construcção d'esse edifício". ${ }^{2}$

A Casa de Oração do Vale de Lágrimas, nome que remete às desgraças humanas após o pecado capital, além dos sofrimentos que seriam pagos por meio de orações no plano terreno, estabeleceu-se enquanto Recolhimento, instituição vista inicialmente como espaço de devoção e vida contemplativa, diferenciando-se dos conventos da época pela ausência dos votos por parte das recolhidas. No dicionário de Rafael Bluteau, a palavra recolhimento

\footnotetext{
${ }^{1}$ ROCHA, José Joaquim da. Memoria histórica da Capitania de Minas Geraes. In: Revista do Arquivo Público Mineiro. Ouro Preto: Imprensa oficial de Minas Gerais, 1897, Ano 2, vol. 3.

${ }^{2}$ PIZARRO E ARAÚJO, José de Souza Azevedo. Memórias históricas do Rio de Janeiro e das províncias annexas à jurisdição do Vice-Rei do Estado do Brasil. Parte II, Tomo VIII. Rio de Janeiro: Typografia de Silva Porto, 1822, p. 191.
} 
aparece caracterizada como: "Casa de religião ou retiro do mundo, sem votos religiosos". ${ }^{3}$ A fundação deste tipo de instituição era mais facilitada pelo fato de ser exigida somente uma licença episcopal para o seu funcionamento, enquanto os conventos necessitavam de uma ordem papal e a aceitação da instalação por parte de uma determinada ordem religiosa. Assim, as recolhidas necessitaram apenas da autorização de D. Jozé Botelho de Mattos, arcebispo da Bahia na época da fundação.

Salienta-se que esta pesquisa considera que a Casa de Oração do Vale de Lágrimas era uma instituição educativa, uma vez que propiciava uma educação devocional das mulheres recolhidas. Segundo Dermeval Saviani, são encontradas acepções diferentes para o significado da palavra instituição: pode compreender a ideia de ordenar, de articular o que está disperso; pode significar instrução e educação; pode formar ou criar algo; e, finalmente, pode aglutinar determinados procedimentos, ideias, crenças e rituais comuns. Entre diversos significados, compreende-se que "(...) a palavra "instituição" guarda a ideia comum de algo que não estava dado e que é criado, posto, organizado, construído pelo homem". ${ }^{4}$

Como as instituições são criadas para satisfazer determinadas necessidades humanas, elas tornam-se unidades que estão sempre em construção e transformação. Constituem-se como um sistema de práticas, com agentes e instrumentos que atinjam as finalidades esperadas. Quando pensa-se em instituições educativas, trabalha-se com um emaranhado de instituições que existem em determinado espaço e tempo para a construção e ordenamento da educação de um determinado grupo social.

Pesquisar as instituições educativas é então desenvolver categorias de análise que dialoguem com o jogo de escalas proposto por Jacques Revel e, segundo este autor, deve-se ocorrer uma mudança de escala de análise, ao partir de interpretações mais amplas e dialogar com conjuntos mais circunscritos, de tamanho reduzido do objeto de análise. ${ }^{5}$ Como trabalhar com uma instituição específica, como exemplo, um recolhimento no sertão da capitania de Minas Gerais, mas a sua ligação direta com uma instituição mais ampla, a Igreja ou o império português no qual vincula-se.

\footnotetext{
${ }^{3}$ BLUTEAU, Rafael. Vocabulário portuguez e latino. Coimbra: Collegio das artes da Companhia de Jesus, 1712.v. 4, p. 297. Disponível em: www.brasiliana.usp.br. Acesso em 15 de junho de 2013.

${ }^{4}$ SAVIANI, Dermeval. Instituições escolares: conceitos, história, historiografia e práticas. In: Cadernos de História da Educação, no. 4, jan-dez. 2005, p. 28. Disponível em: http://www.seer.ufu.br/index.php/che/ article/view/382. Acesso em 02 de janeiro de 2014.

${ }^{5}$ REVEL, Jacques. Da microanálise e construção do social. In: REVEL, Jacques (org.). Jogos de escalas: a experiência da microanálise. Rio de Janeiro: Fundação Getúlio Vargas, 1998. p. 15-38.
} 


\section{Mulheres recolhidas no Sertão}

Alguns documentos analisados apontam para o fato de que o Recolhimento funcionou por um longo período sem autorização e também pelo desconhecimento de sua existência pelas autoridades baianas. Porém, já em um documento datado de 1754, o Arcebispo da Bahia, D. Jozé Botelho de Mattos, faz referências à autorização da instituição e, ainda, informa o recebimento de diversos outros documentos de autoridades da região e até da regente da Casa de Oração, os quais indicavam a situação de funcionamento da casa mantida pelas "mulheres recolhidas no sertão". o Arcebispo também apresenta as suas preocupações pessoais com o local da instalação e o encaminhamento de subsídios para a sua manutenção. ${ }^{6}$

No século XVIII, o sertão caracteriza-se como “(...) o interior, o coração das terras. Opõe-se a marítimo e costa". ${ }^{7}$ O termo definia então a fronteira entre o conhecido e habitado (o litoral) e o desconhecido e pouco habitado (interior). No espaço desconhecido do interior, estabelecia-se a Casa de Oração do Vale de Lágrimas, que era assim descrita por D. Jozé Botelho de Mattos: "Está sito este Recolhimento na parte mais remota deste Arcebispado, apartado 4 legoas da mais vizinha povoação, e em lugar solitário, montuoso e tanto que me seguram causa horror". ${ }^{8}$

No espaço solitário descrito acima, estabelecia-se um grupo de mulheres sem votos religiosos e de várias origens, as quais poderiam solicitar a saída quando desejassem. Verifica-se que havia uma complexidade e diversidade dos tipos de reclusas devido à ausência de estabelecimentos específicos para suprir às necessidades das mulheres da região norte das Minas setecentista. Assim, o recolhimento aqui analisado recebia meninas e mulheres adultas, órfãs, pensionistas, devotas, algumas que se estabeleciam temporariamente para guardar a honra enquanto os maridos e pais estavam ausentes da Colônia ou embrenhados no sertão em busca de ouro, e ainda como esconderijo daquelas consideradas como desonradas pela sociedade da época. Recebeu diversas mulheres, solteiras, casadas ou viúvas para que se

\footnotetext{
${ }^{6}$ D. Jozé Botelho de Mattos. Officio do Arcebispo da Bahia, para Diogo de Mendonça Corte Real, referindose a um Recolhimento de mulheres, fundado no sertão por uma filha do Mestre de Campo da Conquista João da Silva Guimarães e pedindo instrucções a este respeito. 1754. In: SILVA, Cel. Ignacio Accioli de Cerqueira. Memórias históricas e políticas da província da Bahia. Vol. V. Bahia: Imprensa Oficial, 1937, p. 335.

${ }^{7}$ BLUTEAU, op. cit., p. 395.

${ }^{8}$ D. Jozé Botelho de Mattos. Officio do Arcebispo da Bahia, para Diogo de Mendonça Corte Real, referindo-se a um Recolhimento de mulheres, fundado no sertão por uma filha do Mestre de Campo da Conquista João da Silva Guimarães e pedindo instrucções a este respeito. 1754. In: SILVA, op. cit., p. 336.
} 
dedicassem à Oração e à instrução necessária para uma determinada formação religiosa. ${ }^{9}$

Para a compreensão da abertura do Recolhimento, deve-se considerar as especificidades das proibições para a abertura de conventos nas terras mineiras, uma vez que não poderia ter clero regular no território..$^{10}$ Além disso, a dificuldade em alcançar a regulação oficial do poder político pelas instituições femininas passava por outras questões. É possível identificar a necessidade de canalizar a população feminina na Capitania de Minas Gerais para o casamento e o povoamento do território, tornando o incentivo ou a proibição da abertura dos conventos e recolhimentos assuntos centrais das preocupações demográficas da Colônia portuguesa na América. ${ }^{11}$ Segundo Ida Lewkowicz, era muito difícil casar nas Minas setecentistas, uma vez que os brancos livres tinham dificuldade em encontrar mulheres que pudessem desposar devido à sua escassez e o Estado português via nas uniões legitimas uma forma de controlar a população desordeira. ${ }^{12}$ Por outro lado, deve-se atentar que alguns pais preferiam encaminhar as suas filhas para conventos portugueses ou de outras capitanias em vez de casá-las com homens que eram categorizados como abaixo de sua condição social, o que acarretaria também dotá-las de algum conhecimento devocional e alcançar dádivas celestes.

Junia Furtado aponta que a proibição da instalação de conventos e recolhimentos no território foi o coroamento da política de fixação das mulheres na Colônia e o estímulo para a ampliação aos casamentos legais. ${ }^{13}$ Era

\footnotetext{
${ }_{9}^{9}$ ALGRANTI, Leila Mezan. Honradas e devotas: mulheres da colônia - condição feminina nos conventos e recolhimentos do Sudeste do Brasil, 1750-1822. 2a. ed. Rio de Janeiro: José Olympio, 1999.

${ }^{10}$ Segundo Thaís Nívia de Lima e Fonseca (2010), a proibição de entrada do clero regular e de seculares sem paróquia em Minas Gerais foi determinada pela Carta Régia de 9 de junho de 1711. FONSECA, Thaís Nívia de Lima. "Segundo a qualidade de suas pessoas e fazenda": estratégias educativas na sociedade mineira colonial. Revista Varia História. Belo Horizonte, vol. 22, n. 35, jan/jun 2006.

11 “...considerando-se que os povos das minas por não estarem suficientemente civilizados e estabelecidos em forma de repúblicas regulares, facilmente rompem em alterações e desobediências e se lhe devem aplicar todos os meios que os possa reduzir a melhor forma: me pareceu encarregar-vos como por esta o faço/procureis com toda a diligencia possível para que as pessoas principais e ainda quaisquer outras tomem o estado de casados e se estabeleçam com suas famílias reguladas na parte que elegerem para a sua povoação, porque por este modo ficaram tendo mais amor à terra e maior conveniência do sossego dela e conseqüentemente ficarão mais obedientes (...)". D. João V. Sobre fazer casar os moradores das minas e outras partes. Registro de alvarás, cartas, ordens régias e cartas do governador ao rei - 1721 - 1731. In: Revista do Arquivo Público Mineiro. V. 30, Belo Horizonte: Imprensa Oficial, 1979, p. 26.

${ }^{12}$ LEWKOWICZ, Ida. Concubinato e casamento nas Minas setecentista. In: RESENDE, Maria Efigenia; VILLALTA, Luiz Carlos (orgs.). História de Minas Gerais: as Minas setecentistas. Vol. 2. Belo Horizonte: Autentica, 2007, p. 531-547.
}

${ }^{13}$ FURTADO, Junia. As mulheres nas Minas de ouro e diamantes. In: RESENDE e VILLALTA, op. cit., p. 481-504. 
necessário ter mulheres disponíveis para os casamentos, ou seja, em uma ordem inversa, a reclusão de mulheres, particularmente das brancas portuguesas, não poderia ser permitida. Os quadros administrativos da colônia portuguesa até propunham soluções para os problemas casadoiros do território minerador, como indicava em 1721 o governador de Minas Gerais D. Lourenço de Almeida. ${ }^{14}$

Considerando que, no século XVIII, ao governo português não era conveniente à existência de mulheres celibatárias no território mineiro, deve-se então entender as características principais das instalações dos recolhimentos possíveis no território. ${ }^{15}$ Os dois recolhimentos setecentistas de Minas Gerais surgiram principalmente da devoção popular e depois solicitaram a permissão de funcionamento aos bispados e à administração local. Constituíam-se como um lugar misto de devoção, educação e ainda recebiam meninas e mulheres tanto por motivos práticos, quanto religiosos. Para o caso mineiro, salienta-se a ruralidade inicial das instituições, as dificuldades ou até o pouco interesse em serem reconhecidas pelo sistema administrativo colonial, como ainda a necessidade de demonstrar uma religiosidade e vinculação aos seguidores de ermitões. ${ }^{16}$ Verifica-se que, somente em 1780 , quando o Recolhimento do Vale de Lágrimas transferiu-se para o Arraial de Santa Cruz da Chapada, foi que este passou a estabelecer-se em um ambiente urbano e teve uma movimentação das autoridades políticas para a aprovação de sua transferência.

A Casa da Oração, como era considerada inicialmente a instituição aqui analisada, ainda tinha a particularidade de receber mulheres que circulavam

\footnotetext{
14 "Me parece que um dos meios mais fáceis que há para que venham mulheres a casar nestas Minas é proibir Vossa Majestade que nenhuma mulher do Brasil possa ir para Portugal nem ilhas a serem freiras. Porque é grande o número que todos os anos vão (...) se Vossa Majestade lhe não puser toda a proibição, suponho que toda mulher do Brasil será freira, porque me dizem que novamente se faz um convento no Rio de Janeiro, e me parece que não é justo que se despovoe o Brasil por falta de mulheres." (Carta de D. Lourenço de Almeida a D. João V. 1721, Apud ALGRANTI, op. cit., p. 66)

${ }^{15}$ Além da Casa de Oração do Vale de Lágrimas, havia também o Recolhimento de Macaúbas, localizado próximo à Santa Luzia, região central de Minas Gerais. Surgiu em 1715, tornou-se Colégio em 1846 e, em 1926, foi então transformado em mosteiro e passou a abrigar irmãs da ordem concepcionista.

16 "Os recolhimentos criados na região das Minas corresponderam a desejos e necessidades certamente diferentes daqueles que condicionaram o nascimento dos recolhimentos e mosteiros nas cidades importantes da Colônia. Situavam-se no meio rural, em lugares muito afastados dos centros da administração colonial e eclesiástica, e talvez por isso não dependeram e nem sequer buscaram o reconhecimento formal da sua existência por parte do sistema dominante. Também não tiveram a intenção de transformar - se em conventos professos e correspondiam muito à tradição eremítica que se desenvolveu nas Minas, com características que contestavam o sistema colonial, e não à necessidade de criar instituições que fortalecessem esse mesmo sistema." AZZI, Riolando e REZENDE, Maria Valéria. A vida religiosa feminina no Brasil colonial. In: AZZI, Riolando (org.). A vida religiosa no Brasil. Enfoques históricos. São Paulo: Edições Paulinas, 1983 p. 43
} 
no sertão. Toda a documentação analisada até este momento aponta para as irregularidades e dificuldades da vida no sertão pelas recolhidas, o que possibilita uma reflexão acerca das necessidades específicas para a reclusão das mulheres no Vale de Lágrimas, que se protegiam ao formar um grupo, especialmente enquanto os seus pais ou maridos viajavam para Portugal ou embrenhavam-se pelo sertão em busca de ouro, instituindo então um local onde as mulheres exerciam os seus instintos devocionais. Pode-se apontar que este é o caso da primeira regente da instituição, D. Isabel Maria e sua irmã Quitéria, mulheres recolhidas enquanto o pai se embrenhava pelos sertões:

Bastantes annos há, que de palavra e por letra tenho recebido e tomado varias informações sobre hum recolhimento de mulheres de que he fundadora e governante huma D. Isabel Maria, filha do Mestre de Campo da Conquista João da Sylva Guimarães, que há muitos annos, que ajuízo por mais de vinte, que com alguns homens brancos e escravos vive entranhado naquelles sertões, sem comercio de outras creaturas nacionaes, mantendo-se do que trabalha e de algumas porções de ouro, que os Governadores deste Estado lhe tem mandado dar para descobrimento que lhes representa e segura muito capaz para o que tem dom especial. ${ }^{17}$

Em uma região inóspita, com tantas dificuldades para o estabelecimento regular de pessoas, um grupo de mulheres agrupava-se para orar e guardar-se dos problemas externos à instituição. Assim foi o caso das primeiras recolhidas. Alguns documentos apontam para a pobreza do recolhimento: "[...] É de maneira destituído de rendas, que as recolhidas vivem de esmolas." 18 A sobrevivência da instituição por meio de esmolas está presente em quase toda a documentação consultada, inclusive nos relatos de Saint-Hilaire, quando visitou a região em $1817 .{ }^{19}$ Esta também era uma prática comum neste tipo de instituição, uma vez que o hábito de dotar de esmolas os espaços de oração ajudava aos doadores comprarem as suas salvações e, assim, doavam não só dinheiro, mas também alimentos, terras e escravos para a obra das recolhidas.

A Casa de Oração pertencia às mulheres que lá habitavam, sem muita opulência e com cômodos suficientes para abrigá-las. Havia também uma

\footnotetext{
${ }^{17}$ D. Jozé Botelho de Mattos. Officio do Arcebispo da Bahia, para Diogo de Mendonça Corte Real, referindo-se a um Recolhimento de mulheres, fundado no sertão por uma filha do Mestre de Campo da Conquista João da Silva Guimarães e pedindo instrucções a este respeito. 1754. In: SILVA, op. cit., p. 335.

${ }^{18}$ VASCONCELLOS, Diogo Pereira Ribeiro de. Breve descripção geographica, physica e política da Capitania de Minas Geraes. Revista do Arquivo Público Mineiro. 1901, p. 853.

${ }^{19}$ SAINT-HILAIRE, Auguste de. Voyage dans les provinces de Rio de Janeiro et de Minas Geraes. Tomo 2. Paris: Grimbert et Dorez, 1830.
} 
capela anexa, com dois Côros para a celebração do Ofício Divino. Viviam de esmolas, além de alguns trabalhos manuais feitos pelas recolhidas e do trabalho de escravos que eram doados para a instituição. Embora já aceitas pelo poder eclesiástico desde 1754, foi somente em 1779 que as recolhidas solicitaram a confirmação Real para o funcionamento da instituição. ${ }^{20}$

\section{A transferência para o Arraial de Santa Cruz da Chapada}

Segundo documento de 1780 , as Recolhidas foram transferidas do Vale de Lágrimas para um território próximo, o Arraial de Santa Cruz da Chapada, por causa das diversas inundações do rio Araçuaí no primeiro terreno. ${ }^{21}$ Outro documento relata a saída das recolhidas da Casa próxima de Minas Novas e indica que este processo não foi fácil, uma vez que o sertão ermo e os problemas de acesso aparecem para justificar a transferência. A Casa ficava entre dois rios (Araçuaí e Fanado), aos pés de um morro e tornava-se inabitável nos momentos de cheias dos rios:

Dizem a Regente e mais Recolhidas em outro tempo na Caza chamada o Valle
de Lagrimas, erecta pelo Padre Manoel dos Santos e hoje assistentas no Arrayal
da Chapada, que na referida Casa do Valle de Lagrimas por ficar entre o rio
Arassuahy e o Fanado fabricada sobre as próprias ripas daquelle em campo
ermo a muy fúnebre, e debaixo de hum monte experimentarão as Supplicantes
gravíssimas necessidades, tanto corporaes, como espirituaes, por que no
tempo das águas, exedente dos referidos dous rios ficava impedida a conducta
dos mantimentos, e dos Padres que as confessassem, e alem disso por conta da
habitação naquele lugar adquirirão as Supplicantes muitas e graves moléstias,
que hoje padecem sem remédio, como tudo se mostra dos documentos juntos;
ate que as Supplicantes vendo-se assim consternadas aflictas, e doentes e o
que mais he flagelladas do dito Padre erector, e director das Supplicantes.
por motivos que por prudência casão, ainda que bem notórios; evacuarão a
referida Casa do Valle de Lagrimas, com corpo unido buscarão o Arrayal da
Chapada, e nelle se achao congregadas e recolhidas na Caza particular de hum
bemfeitor, que movido de piedade lhe largou, conservando as Suppes. aquelle
bom nome e reputação que sempre tiverao.

${ }^{20}$ ROCHA, José Joaquim da. Memoria histórica da Capitania de Minas Geraes. In: Revista do Arquivo Público Mineiro. Ouro Preto: Imprensa oficial de Minas Gerais. 1897, Ano 2, vol. 3. p. 183.

${ }^{21}$ ABRANCHEZ, Joaquim Manoel de Seixas. Informações sobre o Recolhimento do Arrayal da Chapada, Termo de Minas Novas (1780). In: Revista do Arquivo Público Mineiro. Ouro Preto: Imprensa Oficial de Minas Gerais, V. 02, 1897.

${ }^{22}$ REQUERIMENTO da regente e mais irmãs do Recolhimento do arraial da Chapada no termo de Minas Novas, solicitando confirmação no sentido de erigirem capela dedicada a Santa Ana. 1780. Arquivo Histórico Ultramarino. Caixa 116. Doc. 9194. 
Devido às enchentes e por estarem estabelecidas em uma região de difícil acesso, as recolhidas passavam por necessidades espirituais, devido à falta de confessores e, ainda, necessidades físicas, uma vez que o alimento não chegava às suas terras. Assim, várias mulheres ficaram doentes. Transferiram-se então para Santa Cruz da Chapada, uma vila próxima, onde conseguiram uma habitação temporária. O requerimento acima citado consiste em um apanhado de diversos depoimentos de homens notórios da região e da Comarca do Serro Frio que atestam a seriedade da obra das recolhidas, além de solicitar a abertura de uma nova casa em uma região mais habitável: o Arraial de Santa Cruz da Chapada.

O médico Antônio Xavier Ribeiro diagnosticou que todas as recolhidas possuíam doenças crônicas incuráveis, pois estavam raquíticas, asmáticas e com "fluxos de sangue pela boca". Eram doenças " (...) todas adequeridas na sua morada chamada Vale de Lagrimas, por ser esta cituação mto humida entre matos sem aquelle refrigério mexeu com que se salubriram os corpos, incomunicavel, pesimo e inhabitavel". ${ }^{23}$ Segundo o médico, a mudança para o Arraial de Santa Cruz tornava-se imprescindível para as curas necessárias às recolhidas, tanto espirituais quanto temporais. 0 mesmo documento atesta as virtudes dessas mulheres, além dos direcionamentos educativos esperados na Casa, como indica Antonio José de Araújo:

O viver das sobreditas recolhidas, he com muita virtude, e costumes exemplarissimos, causando pelas suas virtudes, não so admiração, mas também grande contentamento, como he publico e notório; não so nesta Comarca, como em toda a Capitania e lugares mais distantes; e por essa cauza sempre forao estimadas por todos os Excelentissimos Senhores Governadores; e o mesmo pelos senhores Corregedores desta Comarca, e ultimamente por mim. He huma Casa de Oração Seccullar, sem votto algum, utillissima aos pouso deste paiz; por que ali mandão alguns Pays de famílias ensinar suas filhas; tendo as Recolhidas por alguns annos. E dali costumao sahir, não so provectas em Artes Liberaes; mas também no Santo amor, eterno de Deus: também parece útil o dito Recolhimento para em casos semilhantes aos supra referidos, aliviar algum danno de desordem mayor. He o que posso informar a V. Merce com pura verdade; segundo o que me informarão, feitas as indagaçoens, que semilhante matéria pedia. Villa do Bom Sucesso de Minas Novas de junho 23 de $1780 .^{24}$

Pelo documento acima pode-se detectar que eram mulheres consideradas estimadas pela sociedade mineira, especialmente pelas autoridades.

\footnotetext{
${ }^{23}$ Idem.

${ }^{24}$ Idem.
} 
Verifica-se que, após alguns anos de recolhimento, adquiriam uma determinada educação adequada para as mulheres da época: o conhecimento das Artes Liberais e também de práticas devocionais.

Ainda não foi possível encontrar a documentação que autoriza a instalação no Arraial de Santa Cruz da Chapada, mas sabe-se que as recolhidas conseguiram o seu intento, pois uma documentação do mesmo ano de 1780 , já aponta a presença das mulheres em sua nova morada. Pode-se considerar que, neste momento, ocorreu uma melhoria econômica da instituição, pois então já possuíam 36 escravos de ambos os sexos, que plantavam milho, feijão e arroz em três fazendas, provavelmente adquiridas por meio de doações. Em outras duas fazendas criavam ainda gado, embora as suas terras não eram consideradas propícias para a mineração. Havia ainda o pagamento de anuidades pelos pais que recolhiam as suas filhas e diversas doações, o que garantia a auto-suficiência do local. o Recolhimento possuía então no seu interior 12 escravas donzelas para assistir às recolhidas. Contavam com 35 Recolhidas, sendo 33 donzelas e 02 casadas. Estas últimas foram encaminhadas para evitar maiores danos e prejuízos para a honra familiar. ${ }^{25}$ Pelo perfil do público que abrigava no recolhimento neste período, pode-se inferir sobre a necessidade de aceitar ainda uma diversificação em seu interior, não só de moças, mas também mulheres casadas para guardar a honra. Além disso, possuíam um número considerável de escravas para assistir às necessidades das recolhidas e terras que podiam produzir alimentos suficientes para a casa.

Com a mudança para o Arraial de Santa Cruz da Chapada, passaram a utilizar a denominação de recolhimento e substituíram a identificação do Vale de Lágrimas pela proteção de Santa Ana, passando assim a chamar a instituição de Recolhimento de Sant'Anna da Chapada ou, ainda, Recolhimento de São João da Chapada. D. João Botelho de Mattos já fazia menção aos indícios de culto à Sant'Anna, uma vez que as recolhidas no Vale de Lágrimas portavam um hábito como a mãe de Nossa Senhora e até construíram uma capela anexa em devoção a esta santa no terreno inicial. ${ }^{26}$ A capela erguida na nova casa também recebeu o mesmo nome. A devoção à mãe de Nossa Senhora estava muito presente nas Minas setecentistas,

\footnotetext{
${ }^{25}$ ABRANCHEZ, op. cit.

${ }^{26}$ D. Jozé Botelho de Mattos. Officio do Arcebispo da Bahia, para Diogo de Mendonça Corte Real, referindo-se a um Recolhimento de mulheres, fundado no sertão por uma filha do Mestre de Campo da Conquista João da Silva Guimarães e pedindo instrucções a este respeito. 1754. In: SILVA, op. cit., p. 335.
} 
especialmente em terras mineradoras, uma vez que esta é considerada a padroeira dos mineradores. ${ }^{27}$

Em uma região de sertão, onde as mulheres recolhidas possuíam laços com mineradores, as suas orações eram direcionadas à Santa protetora também de seus parentes. Torna-se ainda importante salientar o papel fundamental da Santa na educação de sua filha Maria, o que destaca-se nas obras barrocas, especialmente nas suas retratações enquanto Sant'Ana Mestra. Esta última, a santa representada com um livro aberto e com uma menina atenta ao seu lado, demonstra o papel das mães enquanto educadoras de suas filhas. A santa torna-se "[...] onipresente no catolicismo setecentista das Minas. Mais do que um instrumento do saber, o livro é um canal de comunicação, destinado a Maria e aberto também ao fiel que contempla a imagem" ${ }^{28}$ Entende-se que a relação de sant'Anna com a educação reflete no estabelecimento do recolhimento feminino que se coloca sob a sua proteção e institui-se enquanto espaço de educação no sertão de Minas Gerais.

$\mathrm{Na}$ visão católica, a educação inclui todas as experiências pelas quais se desenvolve a inteligência, se adquire o conhecimento e se forma o caráter. Em um sentido mais estreito, é o trabalho feito por certas agências e instituições. Considerando as especificidades espaciais e temporais, as famílias, escolas, conventos e recolhimentos tornam-se então ambientes propícios para desenvolver a inteligência, o conhecimento e a formação do caráter. Nesse sentido, o caráter que se pretende no ambiente educativo católico compreende principalmente a devoção a Deus.

\section{O letramento religioso na instituição}

A documentação consultada nesta pesquisa aponta algumas pistas para analisar a instrução das recolhidas e ainda a capacidade de letramento que era exigido das mesmas. Pretende-se trabalhar com o conceito de letramento religioso, aqui compreendido por meio dos usos sociais da leitura e da escrita para a formação de uma cultura entre as mulheres que habitaram as instituições religiosas femininas. Na educação de mulheres reclusas, acreditava-se que, quanto maior o letramento voltado para o conhecimento religioso, maior será a aproximação com Deus.

\footnotetext{
${ }^{27}$ Sant'Anna tornou-se padroeira de mineradores - tradição já corrente na Espanha - e de "moedeiros". Assim como as minas, Anna escondia ouro em seu ventre: Maria Imaculada. A analogia teve ressonância no mundo rural das Minas Gerais, alvo das esperanças que colonizadores nutriam há séculos. MELLO e SOUZA, Maria Beatriz de. Mãe, mestra e guia: uma análise da iconografia de Santa'Anna. In: Topoi, Rio de Janeiro: 2002, p. 223-250.
}

${ }^{28}$ MELLO e SOUZA, op. cit., p. 243 
As práticas de letramento podem acontecer em ambientes diversos. Assim, verifica-se a possibilidade de se considerar o letramento religioso, quando as práticas de leitura e de escrita desenvolvem-se em um meio social, com a intencionalidade do desenvolvimento e fortalecimento de uma determinada vertente religiosa. Os múltiplos letramentos variam de acordo com o tempo, o espaço e estão articulados com as relações de poder. Para analisar o letramento como prática social, deve-se levar em consideração que as práticas são eventos mediados por textos escritos. Alem disso, existem letramentos associados com diferentes domínios de vida e são padronizados pelas instituições sociais, têm propósitos e se encaixam em metas e práticas sociais mais amplas e devem ser historicamente situados.

Para as mulheres reclusas, quanto maior o letramento voltado para o conhecimento religioso, maior seria a aproximação destas com Deus. Deve-se levar em consideração as diferenças entre os grupos sociais quanto ao material escrito disponível, quanto aos valores atribuídos à escrita e quanto aos usos que são feitos da escrita e da leitura. No caso do letramento religioso, compreende-se uma indicação de determinados livros e comportamentos necessários para o fortalecimento das práticas devocionais.

Além disso, o letramento religioso acontecia especialmente em situações de diglosia, pois estabelecia uma relação entre duas ou mais línguas, sendo que a língua de prestígio era aquela utilizada na instrução. No caso aqui analisado, o latim tornava-se a língua de prestigio, o que tornava a compreensão dos textos de forma diferenciada pelas leitoras, dependendo da compreensão desta língua por parte de cada uma e da sua interpretação na língua de origem. No século XVIII, verifica-se que algumas obras lidas, especialmente o Breviário utilizado nos momentos do Ofício Divino, era predominantemente escrito em Latim. Quanto às demais obras escritas neste período e possíveis no interior de instituições educativas femininas, aquelas consideradas como edificantes e exemplares, verifica-se que estas seguiam os padrões do vernáculo e eram lidas na língua local.

Alem de pensar nas práticas de leitura, torna-se também necessário dialogar com as práticas da escrita dessas mulheres. Segundo Lígia Bellini, a existência de capacitações desiguais ao saber letrado no interior dos conventos e recolhimentos femininos pode ser estendida à escrita. ${ }^{29}$ É necessário considerar que a cultura escrita é uma construção complexa, sendo que ler e escrever são ações que se conseguem mediante formas diversas e

${ }^{29}$ BELLINI, Lígia. Vida monástica e práticas da escrita entre mulheres em Portugal no Antigo Regime. In: Revista Campus Social, 2006/2007, 3/ 4, p. 209-218. 
heterogêneas. Nem todas as religiosas sabiam ler e/ou escrever. Ler significava entrar em contato com a letra dos textos impressos ou manuscritos, sendo que a escrita pressupunha a decifração e reprodução da letra escrita e, portanto, as mulheres enclausuradas desenvolviam essas habilidades de forma diferenciada.

No interior de conventos e recolhimentos, destacavam-se três tipos de escrita: uma doméstica ou institucional, que levava em consideração a administração da casa; uma de foro privado, como as correspondências; e ainda as autobiografias ou biografias de companheiras de claustro, de vida dos santos ou textos morais edificantes (exemplares). Este último tipo poderia ser doméstico e privado, mas em alguns casos poderia circular para outras casas religiosas femininas. Algumas vezes os manuscritos tornavam-se impressos e ganhavam popularidade entre as mulheres dos espaços institucionalizados. Os livros tinham um caráter devocional, mas também propunham uma formação moral, além de contribuir para o desenvolvimento de habilidades de leitura. ${ }^{30}$

Com relação ao Recolhimento de Sant'Anna da Chapada, não foi possível ainda encontrar indicações das leituras específicas feitas pelas mulheres recolhidas, mas alguns documentos dão pistas para o letramento religioso, especialmente por intermédio de uma educação escrita, pois “(...) dali costumão sahir não só provectas em artes liberaes, mas tambem no Santo amor, e temor a Deos". ${ }^{31}$ Segundo Bluteau, as artes liberais compreendiam gramática, retórica, lógica, aritmética, música, arquitetura e astrologia. ${ }^{32}$ Provavelmente a formação das recolhidas na Chapada não compreendia todas as propostas das Artes Liberais, mas na opinião do autor das informações acerca da instituição, a formação compreendia, além das artes liberais, uma formação devocional.

Na instituição aqui analisada, encontra-se ainda indícios documentais de letramento para a celebração do Ofício Divino, o dever de rezar dado aos religiosos, que aponta para a observância e leitura de determinadas orações em horários específicos, sendo que, geralmente, os textos vinham em latim e estavam contidos nos livros designados como breviários.

Um documento aponta ainda o domínio da escrita pela Regente e das demais recolhidas na Chapada, uma vez que apresenta a assinatura destas

\footnotetext{
${ }^{30}$ ALGRANTI, Leila Mezan. Livros de devoção, atos de censura. Ensaios de história do Livro e da leitura na América Portuguesa (1750-1821). São Paulo: HUCITEC, 2004.

${ }^{31}$ ABRANCHEZ, op. cit., p. 357.

${ }^{32}$ BLUTEAU, op. cit., p. 573.
} 
mulheres. $O$ atestado de boa conduta do Sr. Bernardo José de Almeida, datado de 1781 e escrito pela Regente do recolhimento, Catarina Escolástica do Lado, foi assinado por esta e por trinta e uma recolhidas. ${ }^{33}$ Todas as assinaturas apresentam grafia diferenciada e bem elaborada, o que demonstra que foram várias pessoas que assinaram o documento e que possuíam um grau de escrita mais aprofundado. Também não apresenta nenhuma marca de analfabetismo ou de que uma assinava por outra. Os nomes em homenagem aos santos das recolhidas, especialmente à Sant'Anna, apontam para uma tendência comum nos recolhimentos e conventos, cuja proteção sagrada ou o apadrinhamento eram necessários para a habitação em um local tão distante dos grandes centros habitáveis.

A data do fechamento da instituição é imprecisa, mas encontram-se vestígios do seu funcionamento em 1817, como aponta o viajante Auguste de Saint-Hilaire, quando passou por Santa Cruz da Chapada. Segundo este, as poucas mulheres da comunidade eram já idosas e não aparecia ninguém para substituí-las. As suas impressões sobre a economia local apontam para um decréscimo na produção do ouro e o investimento em plantações de algodão, arroz e hortaliças. A população local não passava de 600 pessoas, sendo na maioria mulatos. Pelo visto, o decréscimo da economia do local refletia-se na manutenção da instituição aqui analisada. No breve relato sobre o recolhimento, aponta caminhos de transformações em seu cotidiano, especialmente quanto ao estabelecimento de uma regra para o direcionamento das ações das recolhidas. Neste momento, as recolhidas eram consideradas freiras pela comunidade local, portavam o hábito das carmelitas e agora seguiam a regra de Santa Teresa. ${ }^{34}$

\section{Conclusão}

Este trabalho pretendeu discutir alguns indícios acerca da História da Casa de Oração do Vale de Lágrimas ou do Recolhimento de Sant'Ana da

\footnotetext{
${ }^{33}$ Regente Catharina Escolastica do Lado; Quiteria Felicyana; Gertrudes Anna da Conceiçam; Joaquina Maria dos Anjos; Leonora Anna da Trindade; Rita de S. Thereza; Bernarda de Jezus Maria; Escolastica Maria de Xpto; Anna Perpetua de Sto. Antonio ; Tereza de Jezus; Anna da Gloria; Ricarda do Espirito Santo ; Rita do Paraizo; Maria da Purificação; Maria da Cruz de Jezus; Quiteria de Sta Anna; Maria Querubina de S. Jose; Francisca Xavier de Jesus Maria; Anna Lourenza das Chagas; Maria do Rozario; Jacinta Maria de S. Jose; Joanna do Amor de Deos; Antonia da Conceição; Rita de Deos; Ignacia de Jesus Maria; Joanna de S. Lucas; Laurianna da Exaltação; Anna Maria do Carmo; Joanna do Espirito Santo; Anna da Mercez; Clara Maria Baptista; Maria Serafim dos Anjos (Atestado passado pelas Irmãs da Casa de Oração e Recolhimento de Santa Ana a Bernardo José de Almeida sobre os serviços prestados gratuitamente a casa. Secretaria do Governo da Capitania. Seção Colonial. SG. CX.11. Doc.21. 16/08/1781. APM).
}

${ }^{34}$ SAINT-HILAIRE, op. cit. 
Chapada no período do seu funcionamento. As fontes encontradas até o presente momento apontam para a presença de algumas práticas de letramento na instituição, mas também propiciam um olhar para as transformações ocorridas no seu interior, tanto no momento da sua mudança de localidade, quanto nas suas orientações. As mulheres recolhidas no sertão mineiro modificaram não só o nome da instituição, mas também as orientações praticadas em seu cotidiano. Nos relatos do seu último visitante que registrou a passagem na casa, este nem sequer cita Sant'Anna, embora as seguidoras de Santa Teresa também cultuassem aquela santa. Salienta muito mais o lado de aproximação das mulheres recolhidas com uma regra instituída e a aceitação dessas mulheres enquanto freiras pela sociedade local. Como ocorreu esta transformação e a instituição da regra das carmelitas ma instituição, ou ainda quais obras eram lidas pelas recolhidas, são questionamentos que só serão elucidados com a busca de novas fontes que poderão preencher as lacunas ainda existentes nesta pesquisa.

Artigo recebido para publicação em 28/10/2014

Artigo aprovado para publicação em 29/10/2014 